\title{
Women of the year: On bubbles, babies and baskets
}

\section{Patricia G. Maritz ${ }^{1}$}

Down-bent astride the rowdy rapids - slim and strong, braids skimming the water -

the hazel-skinned laundresses

Robes of cyan, saffron, vermillion... reflect through the shirred wimple of a capering current,

billowing through white suds and fast fingers

Stain-blended bubbles frisk on the water,

down-blown... adrift, cyclamen, citron and indigo streaked mud marbles the river banks
Garments rinsed, wrung and dried are lifted to the wind, folded into baskets raised to crowns ...

Maiden, sister, mother... bare breasted with robes waist-ward sliding, as infants raveningly clutch at a nipple to mouth

High up a hill...

they wind their way along the footpath, figures diminishing as it curves, until only a basket above the summit bobs

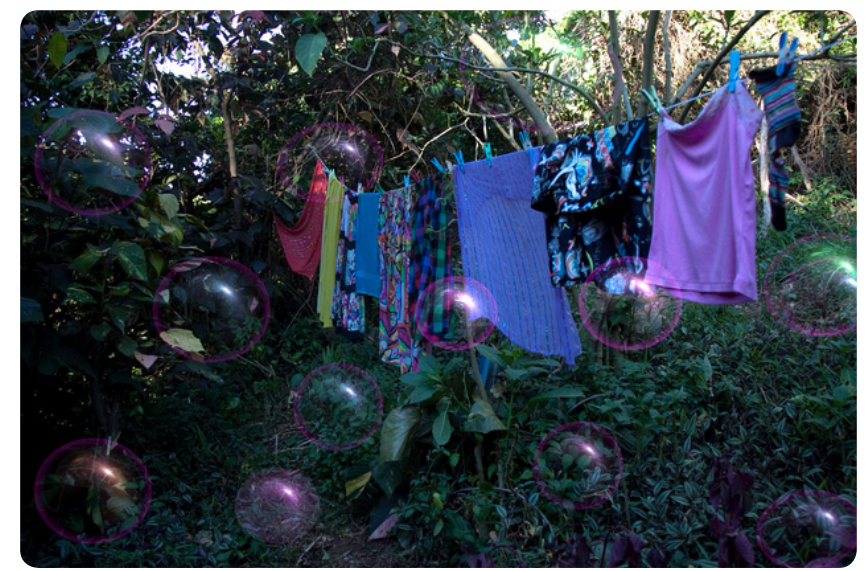

Source: This photo is used with the permission of the author and photographer, Patricia G. Maritz 